\title{
QUILOMBO DAS GUERREIRAS E ZUMBI DOS PALMARES: MOVIMENTOS SOCIAIS PELO DIREITO À MORADIA NA CIDADE DO RIO DE JANEIRO
}

\section{QUILOMBO DAS GUERREIRAS AND ZUMBI DOS PALMARES: SOCIAL MOVEMENTS FOR HOUSING RIGHTS IN RIO DE JANEIRO}

\author{
Monique Falcão ${ }^{1}$ \\ Ricardo Falbo ${ }^{2}$
}

\section{Resumo}

Habitação e urbanização são processos de construção das cidades e sociedades. No Brasil, eles têm fundamentado políticas públicas que não consideram os direitos daqueles que são atingidos pelas reformas urbanas que tais políticas realizam. Neste sentido, a urbanização da cidade do Rio de Janeiro neste início do século XXI parece retomar políticas autoritárias do passado. Projetos esportivos e políticos com o objetivo de potencializar o processo de urbanização e de globalização da cidade do Rio de Janeiro não têm considerado os interesses específicos dos atores que são os personagens da história da própria cidade em que habitam e que ocupam lugar no processo de sua construção. Assim, o direito de moradia das populações de baixa renda que constituem movimentos urbanos de ocupação de prédios públicos abandonados no centro do Rio de janeiro esbarra com as conseqüências desses processos de urbanização da cidade. O objetivo deste artigo é investigar natureza do tipo de relação entre sociedade civil e Estado na cidade do Rio de Janeiro, objetivo esse que depende da condição que atribui aos movimentos de ocupação o status de movimentos sociais.

Palavras-chave: Ocupações urbanas; Movimentos sociais; Habitação; Sociedade Civil; Estado.

\begin{abstract}
Housing and urbanization are processes of construction of cities and societies. In Brazil, they have supported public policies that does not consider the rights of those who are affected by the urban reforms that such policies carry out. In this sense, the urbanization of the city of Rio de Janeiro at the beginning of the 21st century seems to adopt old authoritarian policies of the past. Sporting and political projects aiming to enhance the process of urbanization and globalization of the city of Rio de Janeiro have not considered the interests of the actors who are the characters in the history of the city itself in which they inhabit and occupy a place in the process of its construction. Thus, the right to housing of low-income populations that constitute the urban movements of occupation of the abandoned public buildings in downtown Rio de Janeiro come up with the consequences of these processes of urbanization of the city. The purpose of this article is to investigate the nature of the relationship between civil society and State in the city of Rio de Janeiro. However, this goal depends on the condition that assigns to the movements of the occupation status of social movements.
\end{abstract}

Keywords: Urban occupations; Social movements; Housing; Civil society; State.

\footnotetext{
${ }^{1}$ Doutoranda em Direito na Universidade do Estado do Rio de Janeiro - UERJ. Professora da Universidade Santa Úrsula - USU. E-mail: mqfalcao@gmail.com Pós-doutorado em direitos humanos pela Université Paris 2. Professor adjunto da Faculdade de Direito da Universidade do Estado do Rio de Janeiro - UERJ. E-mail: neryfalbo@gmail.com

2 Pós-doutorado em direitos humanos pela Université Paris 2. Professor adjunto da Faculdade de Direito da Universidade do Estado do Rio de Janeiro - UERJ. E-mail: neryfalbo@gmail.com
} 


\section{INTRODUÇÃO}

Habitação e urbanização são processos de construção das cidades e sociedades. No Brasil, do ponto de vista histórico, eles têm instrumentalizado políticas públicas que não consideram os interesses e os direitos daqueles que são atingidos pelas reformas urbanas que tais políticas realizam. No início do século XXI, a urbanização da cidade do Rio de Janeiro parece retomar políticas autoritárias do passado, na medida em que elas não levam em conta a história e os interesses específicos dos atores que são os personagens da história da própria cidade em que habitam e que ocupam lugar no processo de sua construção. O governo federal de Fernando Henrique Cardoso e de Luís Inácio Lula da Silva e os governos municipais da cidade do Rio de Janeiro de Cesar Maia e de Eduardo Paes executaram - e ainda executam - projetos a um só tempo esportivos e políticos (a Copa do Mundo de 2014 e os Jogos Olímpicos de 2016, por exemplo) com o objetivo de potencializar o processo de globalização da cidade do Rio de Janeiro (COMPANS, 2005).

Daí a intervenção do poder público (municipal, estadual e federal) para atrair investimentos e capitais estrangeiros para a cidade. Daí também as políticas públicas de reforma urbana voltadas para o meio ambiente e a arquitetura, para as atividades econômicas e comerciais, para a requalificação e acessibilidade da região central da capital fluminense. Consequentemente, o direito de moradia das populações de baixa renda que constituem movimentos urbanos de ocupação de prédios públicos abandonados no centro do Rio de janeiro esbarra com as consequências desses processos de urbanização da cidade, que não consideram tais ocupações como atores sociais que fazem historicamente parte da cidade e que ajudaram - e ainda ajudam social e culturalmente na sua construção.

A realidade em questão - palco das manifestações dos movimentos sociais e dos atores sociais neste trabalho - diz respeito a duas ocupações de prédios públicos abandonados no centro da cidade do Rio de Janeiro e que foram ocupados por membros das camadas da população de baixa renda que não tinham onde morar ou que reconheciam sentido específico em morar no centro da cidade. São elas as ocupações Zumbi dos Palmares e Quilombo das Guerreiras.

Tais ocupações reivindicam o direito à moradia no centro da capital fluminense, e não o direito de morar necessariamente próximo ao local trabalho, reivindicação cuja natureza se afasta da compreensão clássica que articula trabalho e moradia e assim fundamenta historicamente a produção da cidade (ENGELS, 2008). Conforme fora demonstrado pela pesquisa exploratória e de 
campo, a dignidade referida ao direito de morar no centro da cidade diz respeito à proximidade dos centros de informação e serviços.

O principal objetivo que se procura alcançar neste trabalho é a definição da natureza do tipo de relação entre sociedade civil e Estado na cidade do Rio de Janeiro, objetivo esse que depende da condição que atribui aos movimentos de ocupação o status de movimentos sociais. Desta forma, a investigação empírica dos movimentos de ocupação urbana poderá contribuir para pensar a redefinição da relação que articula "sociedade civil" e "Estado" quanto ao caráter mais democrático ou menos autoritário da gestão da cidade do Rio de Janeiro. Quanto a esta tarefa, as Ocupações urbanas investigadas na capital fluminense - e abordadas enquanto movimentos sociais - serão aproximadas, de forma analítica, do chamado "terceiro setor".

Compreendido na sua referência ao primeiro setor (o Estado) e ao segundo setor (o mercado), o terceiro setor é definido neste trabalho quanto ao caráter não governamental e não lucrativo das atividades e serviços das organizações sociais (FERNANDES, 1994). Por movimento social se entenderá todo protesto de caráter moral que, não procurando mudar a estrutura social, objetiva a mudança de estilo de vida (TOURAINE, 1979).

Do ponto de vista operacional, de modo a subsidiar a análise dos movimentos sociais e do terceiro setor, os conceitos de Estado e sociedade civil são definidos de acordo com o pensamento de Antonio Gramsci. "Por enquanto, podem-se fixar dois grandes 'planos' superestruturais: o que pode ser chamado de 'sociedade civil' (isto é, o conjunto de organismos designados vulgarmente como 'privados') e o da "sociedade política ou Estado", planos que correspondem, respectivamente, à função de 'hegemonia' que o grupo dominante exerce em toda a sociedade e àquela de 'domínio direto' ou de comando, que se expressa no Estado ou no governo 'jurídico" (GRAMSCI, 2000:21-22, v 2). O Estado também é assim definido: “além do aparelho de governo, também o aparelho 'privado' de hegemonia ou sociedade civil" (GRAMSCI, 2000: 254-255, v 3).

A escolha da habitação como área da vida social decorre do déficit mundial de moradia para as camadas sociais as mais desfavorecidas. A escassez de habitação com função social já fora denunciada pela ONU como uma das principais causas da miséria no mundo. Daí a importância deste trabalho também para a sociedade internacional e para a sociedade global, onde o desrespeito pelos direitos humanos significa a perpetuação desse quadro de penúria de moradia social. Daí a possibilidade se repensar as relações entre sociedade civil e Estado na chave da atuação coletiva dos movimentos de ocupação urbano em torno do direito à habitação como 
direito fundamental de existência social do homem - onde quer que ele se encontre num dos quatro cantos do mundo - do qual dependem os demais direitos.

Do ponto de vista metodológico, a hipótese deste trabalho será investigada segundo a possibilidade de traduzir o pensamento sociológico prático sobre o direito que formulam os movimentos de ocupação e de acordo com metodologia que procure a superação das oposições clássicas, tais como a dicotomia "sociedade civil-Estado". A metodologia que traduz esta visão e que permite lidar com a redefinição das relações entre sociedade civil e Estado através da investigação empírica dos movimentos de ocupação urbana é a etnometodologia de Garfinkel. As atividades práticas, as circunstâncias práticas e o raciocínio sociológico prático definem o campo de pesquisa da etnometodologia (GARFINKEL, 1992). Sem excluir a observação dos atores e de seus campos, a técnica de coleta de material no âmbito desta pesquisa consistirá na realização de conversas e entrevistas. De acordo com esta técnica, os dados obtidos serão sempre remetidos às suas circunstâncias particulares de interações específicas (MYERS, 2002).

\section{MOVIMENTOS DE OCUPAÇÃO ZUMBI DOS PALMARES (OZP) E QUILOMBO DAS GUERREIRAS (OQG)}

Zumbi dos Palmares e Quilombo das Guerreiras são expressões de movimentos sociais que decidiram, como estratégia de reivindicação de moradia digna, pela ocupação de prédios públicos ${ }^{3}$ no Centro da cidade do Rio de Janeiro.

Em abril de 2005, mais de 100 pessoas ocuparam o prédio do INSS localizado na Avenida Venezuela, 53, fundando a OZP, e em outubro de 2006, mais de 150 famílias ocuparam o prédio da DOCAS, localizado na Avenida Francisco Bicalho, 49, ambos na zona portuária, no centro do Rio de Janeiro.

Diante do estado de abandono dos imóveis, os ocupantes procederam à limpeza e deram início à recuperação das instalações elétricas, sanitárias e hidráulicas. "A comissão de manutenção era formada por moradores, que eram eletricistas, pedreiros, e aceitavam cuidar do prédio". ${ }^{4}$ Quanto à prestação de serviços públicos, Janine, da OQG respondeu, em relação à luz elétrica, que "nada chega até nós"; que "a luz é nossa"; "o gás, a gente compra" (também água); que, em relação à

\footnotetext{
${ }^{3} \mathrm{O}$ caráter público desses prédios diz respeito à natureza jurídica de seus proprietários. O INSS é autarquia federal vinculada ao Ministério da Previdência Social, onde está a Ocupação Zumbi dos Palmares e a Companhia Docas do Rio de Janeiro é sociedade de economia mista vinculada ao Ministério dos Transportes, onde está a Ocupação Quilombo das Guerreiras.

${ }^{4}$ Valentim, 02/09/2011.
} 
coleta de lixo, esta é feita pela COMLURB (duas vezes por dia); e que há entrega de correspondências pela ECT (duas vezes por semana). Roberto, também da OQG, afirma que chegou a ir ao Ministério das Cidades, em Brasília, para apresentar as reivindicações do movimento de ocupação (saneamento básico, energia, etc.); que não conseguiu chegar ao ministro "mas fui bem recebido" ("com direito a água gelada e café"); que não conseguiu a resolução do problema, por que $o$ atendimento fora superficial e burocrático, tendo-Ihe sido recomendado que "procurasse $o$ presidente da light no Rio, pois lá nada poderiam fazer." Já, no Rio de Janeiro, as tentativas também foram em vão, pois diziam não ser possível levar água/energia até o local ou adiavam a tomada de solução.

Em ambos os casos, a preparação e a organização para as ocupações se deu com muitas reuniões entre os candidatos e os que já estavam articulando as ocupações. Os candidatos se apresentavam para serem escolhidos ou rejeitados pelos integrantes mais antigos dos movimentos de moradia. Os critérios de seleção tinham por objetivo aferir a confiança que os candidatos apresentavam ao grupo já existente. Investigavam-se a aderência aos interesses comuns e coletivos, a compreensão dos ideais e os conceitos de moradia digna, direito, luta, e aferia-se quem tinha necessidade de moradia. A educação tinha função integrativa, de coesão: "Orientar os moradores analfabetos" conscientizar para lutar pelo direito"7. O objetivo dessas reuniões é "conscientização social e política", "informação" e estabelecimento dos "procedimentos da próxima ocupação". 8

Essa lógica de seleção se manteve na OQG para aceitação e rejeição de novos candidatos à ocupação já instituída, de forma que o coletivo, em "assembléia", rejeita e impõe sanções, inclusive a de expulsão, a integrantes que não se alinharem aos interesses e regras comuns, estabelecidas no "regimento interno" da ocupação. Os casos envolvendo drogas, violência e comercialização de espaço são considerados graves e desviantes, sendo objeto de punição pelo coletivo.

Janine, da OQG, afirma que "não é muito comum as pessoas pedirem pra sair da ocupação", que a maioria entre os que saíram arrumou condições melhores, mas alguns saíram por "falta de ambiente". Já na OZP, a instituição da ocupação se deu mediante estes mesmos critérios, mas sua manutenção não os seguiu. Segundo Valentim, houve "traição" e "dissidência" entre os integrantes

\footnotetext{
${ }^{5}$ Valentim, 02/09/2011.

${ }^{6}$ Antonia, 27/01/2011.

${ }^{7}$ Valentim, 02/09/2011.

${ }^{8}$ Roberto Gomes dos Santos, 31/08/2010.
} 
da ocupação. Ele afirma que alguns moradores se afastaram da proposta do grupo: "Nossa proposta era moradia para as classes pobres". pessoas que "vieram de outras ocupações não organizadas" e que "eles vendiam o espaço para outras pessoas"; eles são os chamados 'profissionais da ocupação'. Por fim, ele reconheceu que "havia também desvio de doações, vendas de doações", que recebiam de empresas, o que definiu como "individualismo", "individualistas". Outros problemas internos, como o uso e tráfico de drogas, bem como homicídio, foram relacionados a esse "nosso descuido" na seleção inicial de integrantes e em não estabelecimento de regras de convivência, a exemplo do regimento interno da OQG: "Queriam levar para a Ocupação (Zumbi) a situação (tráfico de droga) da Comunidade". Valentim e outros entrevistados atribuem a dissidência à "gente sem conhecimento da causa [da moradia] que era usada pelos outros", sendo estes "outros" o que chamou de "infiltrados", isto é, pessoas de grupos de interesses próprios diversos do da moradia, como empresários e "os funcionários da Prefeitura", que, interessados na desocupação do prédio para o projeto Porto Maravilha, ofereciam dinheiro aos "dissidentes".

O conceito de moradia digna por esses grupos passa pela concepção de moradia no Centro, o que significa "acesso a possibilidades de atividades"; afinal, trata-se de local onde se encontram melhores condições de trabalho, maiores rendimentos financeiros e melhores serviços públicos de transporte, saúde e educação, "condições de vida que não têm na Baixada, as ruas não são asfaltadas, 3 horas de ônibus para chegar ao centro". São esses critérios que também caracterizam a "necessidade de moradia". 10

Exercer e ter cidadania, para esses grupos, é exercer direitos com luta, reivindicando-os do poder público, mediante atos e formas de pressão, dentro do que compreendem por legalidade, que é obter, pelas próprias mãos, o que o poder público deveria conceder por direito. O direito só é válido e eficaz se for praticado e reivindicado. "Me vejo cidadã assim: foi uma luta, não comprei esse espaço, mas lutei, melhorei, limpei. A luta da Ocupação Zumbi dos Palmares é por morar no centro da cidade, não necessariamente neste prédio. É trabalhar de alguma forma, lutar, conquistar, valorizar, participar. " ${ }^{11} O$ objetivo aqui é um só, a moradia. (...) Viemos pra cá com a idéia de permanecer (...) Eu tinha que ser um cidadão completo, participar da questão social." 12

\footnotetext{
${ }^{9}$ Valentim, 02/09/2011.

${ }^{10}$ Valentim, 02/09/2011.

${ }^{11}$ ANTONIA FERREIRA DOS SANTOS, 35 anos, união estável, 3 filhas, artesã e cuidadora de idosos, cearense. 27/01/2011.

12 Roberto Gomes dos Santos, 31/08/2010.
} 
A ocupação seria uma atitude legal, que dever ser reconhecida e aceita pelo poder público, porque compreendem que "estamos ocupando o que é nosso. Pagamos por isto. Pagamos impostos"13. Eles afirmam também terem sido bem recebidos pelos que ocupam as redondezas. $\mathrm{Na}$ OZP, "no início houve resistência. As Lojas Americanas aplaudiram a Ocupação. Ela mudou a estratégia para o convívio. Tinham pessoas antes debaixo das marquises.". Com isso, eles justificam que "prédio abandonado é sem fim social." 14

A luta por moradia digna, para ser reconhecida como legal, deve restringir-se a morar e não a ter moradia, mantendo-se afastada da especulação imobiliária, prática mercadológica e estatal tida como prejudicial à distribuição de moradia para quem necessita. Daí Juvenal, da OZP, criticar os 'profissionais da ocupação', porque "o espaço é para quem precisa dele para morar". Juvenal afirma que melhorar de vida através da ocupação e poder sair dela por ter casa para morar não dá direito ao ex-morador receber dinheiro por repassar o espaço; ele argumenta que mesmo quem fez investimento no espaço - realizou obras e melhorias - não tem direito a receber esse dinheiro de volta do ocupante seguinte, porque "este outro virá morar porque necessita" e, portanto, não terá dinheiro para 'comprar' o espaço; que essa prática é "pior que a prática do Estado, por que parece especulação imobiliária." ${ }^{\prime 15}$

A relação com o poder público funda-se nesta dialética entre exigir (que implica praticar) o que se entende por moradia digna e questionar as políticas públicas de moradia realizadas pelo governo. Há busca por reconhecimento de condutas legais paralela e simultaneamente ao questionamento de eficiência do aluguel social, das indenizações oferecidas pelo Poder Público para a desocupação e da localização e qualidade dos conjuntos habitacionais oferecidos aos moradores. Para Valentim, governar é "administrar o que é nosso". "É obrigação deles". "O governo está despreparado". "Minha casa, minha vida é para os pobres. Mas quem ganha? As construtoras". "Onde ficam estas casas? Qual a qualidade delas?". ${ }^{16}$ Juvenal e Valentim lamentaram o fato de a Prefeitura não ter aceitado proposta de "ficar no prédio até que as casas do Livramento fossem construídas", considerando que "se tem pressa [de desocupar o prédio] por que não fazem mais rápido as casas do Livramento? A Prefeitura tem pressa, mas não quis se

\footnotetext{
${ }^{13}$ Valentim, 02/09/2011.

${ }^{14}$ Valentim, 02/09/2011.

15 Juvenal, 25/01/2011.

${ }^{16}$ Valentim, 02/09/2011.
} 
apressar. Tão levando pessoal na barriga. Quando eles querem fazer rápido, sai tudo rápido, mas para pobre, não sai nada. "17

Respectivamente, quanto à indenização de $\mathrm{R} \$ 20.000,00$ e ao aluguel social, compreendem que "não dá para comprar nada aqui; se pagar aluguel, acaba em 1 ano e a gente tá na rua de novo; teve uma (moradora) que teve serrar a cama para caber num quartinho, vai dormir com perna encolhida. Pessoal jogou sofá fora, geladeira, porque não tem como levar, não tem onde botar, aí deixa para aí. Tem outra (moradora) aqui que tem 11 filhos, onde ela vai botar todo mundo. Qualquer aluguel aqui tá $R \$ 600,00, R \$ 700,00 . " 18$ Quanto às casas populares em Vila Kosmos, elas também foram rejeitadas por grande parte dos moradores da OZP, por ser longe do Centro: "pobre não tem direito de morar no Centro; rico que tem que morar longe por que tem carro para vir; longe tudo é difícil, escola". "o Governo pega o pobre e joga para lá, e morre lá mesmo". 19

Sobre o programa Minha Casa, Minha Vida, Roberto, da OQG, disse que "minha casa minha vida é furada", porque "o limite para pagar é muito caro", que "os valores não são compatíveis com os nossos salários". Criticou o programa afirmando que a proposta que a Caixa Econômica Federal fez, em visita aos moradores da ocupação, "com um monte de gente, um monte de papel e uma pompa danada", era distante da realidade deles: que a parcela de $\mathrm{R} \$ 400,00$ ou $\mathrm{R} \$ 600,00$ era excessiva para ele, por exemplo, que ganha $\mathrm{R} \$ 1.200,00$ por mês, como servidor público da Aeronáutica. Disse que "não confio na Dilma", porque os programas anunciados como populares não atendem suas necessidades.

Sobre a possibilidade de se mudar para outros lugares, Roberto, da OQG respondeu que "já tinha até casa pronta pra nós em Sepetiba e Santa Cruz. Sem desmerecer esses lugares, mas a fonte de renda tá no Centro". Ressaltou que "o objetivo aqui é um só, a moradia"; "viemos pra cá com a idéia de permanecer". Sobre sua vinda para a ocupação, Roberto afirmou que, mesmo morando na casa dos seus pais, "eu tinha que ser um cidadão completo, participar da questão social".

Roberto confirma que a importância da identidade de luta se sobrepõe ao conforto (que para ele seria um imóvel com infra-estrutura básica). Sobre o Projeto Gamboa, afirma que "é uma troca"; trata-se de um "conjunto habitacional" (apartamentos) a ser construído no terreno ao lado da "Cidade do Samba", "também na zona portuária", cuja previsão para entrega é o final do ano de 2012. Embora ache mais acessível financeiramente (parcelas de $10 \%$ da renda mensal do

\footnotetext{
17 Valentim, 25/01/2011.

18 Juvenal, 25/01/2011

19 Juvenal, 25/01/2011.
} 
adquirente do imóvel), pode "não ser tão pacífico como o quilombo" e disse ter receio de que a "história material" "se dissolvesse". Admite a possibilidade de "damos o prédio para a Docas e ganhamos moradia"; "já escolhemos até um nome: 'Quilombo da Gamboa". Mas pondera que "lá vai ser outra ocupação, a gente vai perder a nossa identidade"; "a gente nem pensa na questão do conforto, a luta se sobrepõe". Roberto disse que não quer ir com medo de a "identidade adquirida ao longo da lutase perder" e que quando entraram na ocupação "não" tinham noção que "construiriam uma identidade", mas que queriam ali permanecer e que eles não se mudaram para ali querendo, que se mudaram "como se fosse uma ocupação provisória"; agora, eles sabiam que desde sempre queriam permanecer ali.

Sobre a construção da identidade coletiva, Roberto a relaciona à união dos integrantes da ocupação e aos interesses comuns do coletivo. Roberto afirma: "não quero sair daqui para nenhum outro lugar". E isto em função de já ter "constituído raízes" e por respeito e desejo de manter a "história da luta viva" e também em função das "vantagens" que o "ponto" oferece: paz, proximidade com o centro da cidade, onde tem trabalho para todos, principalmente para os que têm trabalho informal. Tais dizeres foram confirmados por Janine. Daí o fato de eles considerarem as propostas do poder público como não sendo interessantes. Sobre as relações com as autoridades, Janine afirmou que "quase não aparecem" e que "eles propõem outras formas de moradia, mas não serve". Sobre o Projeto Gamboa, que prevê 140 unidades habitacionais, afirmou que, "mas aqui já temos nosso jeito, nosso espaço". Justificou que poderia haver "dificuldades de adaptação", "desarticulação coletiva". Sobre a possibilidade de se mudar para a Zona Oeste, receber imóvel com infra-estrutura, Janine respondeu: "não, Deus me livre! ", "a nossa vida tá aqui", "nada de aluguel social". Afinal, morar no Centro significa proximidade em relação a escolas, hospitais e transportes e, além disto, eles podem levar as crianças à praia no sábado e no domingo: "fica mais barato e mais perto".

Roberto informou que "a maioria [dos integrantes] quer ir para o Projeto Gamboa". Perguntado sobre o que quer a minoria, que inclui ele e Janine, ele respondeu: "Vamos trazer outras pessoas pra cá, pessoas que moram nas ruas, que não podem pagar aluguel"; "o que não falta é gente precisando de lugar pra morar".

Nas duas ocupações investigadas, foi comum a afirmação segundo a qual aqui "não tem liderança, nem por antiguidade, nem por nenhum outro critério" nem "coordenação". Na Quilombo das guerreiras e na Zumbi dos Palmares, tem o "sistema de votos". Roberto afirmou que há ainda 30 "integrantes do coletivo" que participam da ocupação desde o início, mas que "antiguidade aqui 
não é posto". Eles protegem a ocupação e a si mesmos de serem identificados em processos judiciais. Valentim, não se reconhecendo como chefe quando assim fora apontado pelo oficial de Justiça que fora à OZP, para proceder à interdição do local, disse: "Eu sou morador". Impedido então de sair da Ocupação, outros moradores disseram: "É com a gente". "Aí eles [oficial de justiça] ficaram sem ação". Entretanto, o contato com seus membros com o objetivo de realizar entrevistas sempre foi mediado por Roberto, da OQG, e por Valentim, da OZP, sempre presentes e acompanhando a realização das entrevistas quanto a membros por eles escolhidos para serem entrevistados. Quanto às relações com outros movimentos, Janine afirmou que com a Chiquinha Gonzaga "é o mais forte", que com a Zumbi dos Palmares e Machado de Assis, "nem tanto". Segundo ela, essas relações ocorrem através de "encontros", "festas abertas ao público", mas que não há intercâmbios nas reuniões dos movimentos. Roberto afirmou que "estamos sempre em contato", "mas sem participação nas reuniões uns dos outros."

\section{ETNOMETOdOLOGIA: QUESTÕES DE MÉTODO}

Garfinkel construiu um modelo de pesquisa empírica referido ao mundo concreto da vida cotidiana de seus agentes. Em contextos sociais tão distintos quão diversos, a compreensão das ações sociais torna-se dependente da análise do raciocínio prático desenvolvido pelos agentes e dos procedimentos por eles utilizados para alcançar seus fins e atribuir sentido às suas práticas sociais (GARFINKEL, 1992).

O pensamento de Harold Garfinkel se constituiu como ofensiva crítica à sociologia clássica, principalmente à tradição representada pela sociologia de Talcott Parsons, que procurou explicar o funcionamento das estruturas sociais e os processos de racionalização das ações sociais. Para o autor de Ensayos de teoría sociológica, "além de constituir a 'espinha dorsal' de orientação de ação de todos os sistemas sociais existentes, as instituições definem as condutas legitimamente esperadas e desejadas" (PARSONS, 1967, p. 207). A consequência que daí decorre é a situação de subordinação e de redução da racionalidade e da ação dos agentes sociais a padrões normativos considerados como social e legitimamente institucionalizados.

Como afirma Garfinkel (1970, p. 339), "entendemos que a pessoa, ao falar uma linguagem natural, está comprometida de alguma maneira com a produção e apresentação objetivas do conhecimento de senso comum quanto a seus assuntos cotidianos enquanto fenômenos observáveis e relatáveis". E os fatos sociais são realizações das pessoas, ou membros. A noção de "realização dos membros" adotada pela etnometodologia supõe a produção de práticas contínuas 
pelos agentes sociais. Consequentemente, a realidade social, associada à ideia de ordem, estabilidade e equilíbrio, não é vista nem como "dado" nem como "coisa", e sim como processo, permanente e contínuo.

Neste sentido, normas e regras não são consideradas como estruturas significativas estáveis, preexistentes e independentes das interações sociais, às quais aderem os atores sociais. Elas são construções práticas e circunstanciais que definem e revelam os raciocínios sociais práticos e os métodos utilizados pelos agentes sociais em suas interações sociais, cuja realização depende da interpretação do mundo segundo aqueles mesmos raciocínios e métodos e do uso da linguagem que fazem os agentes sociais na comunicação do conhecimento de sentido comum.

Outro conceito importante da etnometodologia de Garfinkel é o de reflexividade, que pode ser definida como a propriedade das práticas dos agentes sociais que permite descrever e que constitui determinado quadro social. Neste sentido, no momento de sua expressão,as descrições do social se transformam em partes constitutivas da própria realidade descrita (GARFINKEL, 1970). E a "accountability" das atividades cotidianas e de suas circunstâncias traduz a reflexividade de que é constituída toda prática social, isto é, a capacidade que possui a descrição de constituir o próprio quadro social como sendo "accountable". Referida à reflexividade, a "accountability" supõe ainda a racionalidade ou inteligibilidade das práticas sociais. Garfinkel parte da ideia segundo a qual os discursos práticos se caracterizam pela "indexabilidade", isto é, a significação dos mesmos depende do contexto em que eles existem (GARFINKEL, SACKS, p. 339)

Partindo do princípio segundo o qual a etnometodologia está interessada em descobrir os procedimentos que os membros utilizam para chegar ao conhecimento do senso comum no curso de suas interações e assim organizar sua vida social cotidiana, comum, a realização de conversas e de entrevistas constituem igualmente técnicas de coleta de material no âmbito dos trabalhos etnometodológicos. Se o modo como os membros de um grupo social utilizam os discursos e as expressões da vida cotidiana permite determinar a posição de suas experiências e de suas atividades (CICOUREL, 1977, p. 60), ele também permite definir o fundamento do raciocínio sociológico prático.

A análise da conversação e da fala (MYERS, 2002) é técnica que permite alcançar esse objetivo. Segundo esta técnica, os dados obtidos com a realização de entrevistas e a observação de atores e campos devem ser remetidos às suas situações particulares de interações específicas (MYERS, 2002, p. 271). Os dados devem ser considerados como atos de fala e de conversação. Como tais, os dados não considerados como possuindo nenhuma propriedade ou status especial 
que justifique a separação ou a hierarquização dos mesmos (MYERS, 2002, p. 272). Assim analisados, os dados permitem identificar as categorias de pensamento dos membros de um grupo social investigado, bem como a importância destas categorias para os mesmos e as suas opiniões. Os membros da investigação definem o referencial da análise. Segundo Myers, a análise dos investigados não pode ser realizada de forma independente do investigador e das circunstâncias da interação da pesquisa. A técnica da análise da conversação e da fala se volta para o conhecimento do modo de organização das interações pelos participantes da pesquisa (Myers, 2002, p. 272) e permite pensar a pesquisa e o papel do pesquisador na sua realização.

\section{MOVIMENTOS DE OCUPAÇÃO ZUMBI DOS PALMARES E QUILOMBO DAS GUERREIRAS: ANÁLISE ETNOMETODOLÓGICA}

Para fins de compreensão metodológica, ressalta-se que os entrevistados não definem amostras que possuam a virtude de corresponder à tradução ou representação da realidade dos moradores das ocupações. Os assim chamados dados da pesquisa estão referidos a fontes diretas de conhecimento, isto é, a entrevistas com líderes e moradores que por aqueles foram indicados, e a 'fontes indiretas', isto é, quanto às informações prestadas pelos entrevistados em relação aos demais moradores. Os entrevistados foram considerados como membros de suas Ocupações. Para Garfinkel, a categoria "membro", enquanto objeto de análise das atividades ordinárias, é a unidade que permite revelar a expressão objetiva que reúne condutas individuais em torno de um mesmo fim coletivo, capazes de concretizar a organização e a manutenção do grupo.

O fato social 'interesse em morar no centro' pode ser analisado, pela etnometodologia, através da convergência entre os interesses coletivo e pessoal dos moradores. Composto pela visão mais subjetiva de 'obter moradia digna'(no Centro)' e pela concepção mais objetiva de 'falta de moradia', o 'interesse em morar no centro' apresenta características distintas nos períodos de 'pré-ocupação' e 'durante a ocupação'.

Durante o período que precedeu às Ocupações, a reflexividade foi observada quanto às facilidades referentes à possibilidade de moradia no centro da cidade, isto é, obter moradia decente com base em imóveis velhos e abandonados, considerados, assim, sem valor. Os critérios objetivos fornecidos pelos moradores para caracterizar a moradia como sendo decente (transporte, saúde, educação, acesso a salários mais elevados) são a descrição da sociedade real, produzida como "uma profecia do que ocorre". Neste caso, a ideologia propagada pelas autoridades e investidores - que consideram o aumento da oferta de melhores trabalhos, 
melhores condições de vida, acesso a melhores serviços públicos, da forma mesmo como tudo isto fora descrito pelos moradores - constitui fator fundamental que explica a moradia no centro.

Considerando os interesses pessoais de moradores específicos, eles revelam interesses prévios quanto à moradia no centro da cidade, tais como deixar de morar com os pais, de pagar aluguéis elevados, embora tudo isto implique morar em condições mais precárias, em termos de infra-estrutura. Em ambas as Ocupações, o movimento social que elas realizam se desenha em torno de critérios comuns tanto de caráter objetivo quanto de caráter subjetivo. Sair do aluguel caro, da casa de parentes e dos pais e buscar moradia própria no Centro, a fim de ficar mais próximo do 'trabalho', tudo isto significa exercer o direito de liberdade, o direito de buscar trabalho em condições dignas, enfim, significa participar da questão social. Trata-se de movimento social que reivindica para si direitos que também são reivindicados pela sociedade mais ampla. A diferença está no acesso aos bens reivindicados e na efetividade das reivindicações feita por estas forças determinadas (movimentos sociais) e das reivindicações feitas pela sociedade civil, amplamente considerada, através dos meios formais democráticos.

O "membro" do movimento social, enquanto integrado culturalmente, compartilha concepções objetivas comuns de reflexividade. Ele está presente tanto na fase inicial como na fase de desenvolvimento das Ocupações. No caso da OZP, mais precisamente na fase final da ocupação. $\mathrm{Na}$ fase inicial, as duas ocupações organizam-se em atividades de manutenção do prédio e da instalação de rotina e proteção do coletivo; na fase de desenvolvimento da ocupação, os membros da OQG aderem ao Regimento Interno, que deve ser seguido por todos os moradores. Ele contribui a manter a unidade e a coesão do grupo.

Quanto à construção de regras e normas para a manutenção das Ocupações - bem como seu descumprimento, apontado como causa para dissolução da OZP -, elas são consideradas como construções práticas e circunstanciais decorrentes dos locais anteriores de moradia dos membros, de sua qualidade de vida econômica e social, dos anseios pessoais para obter moradia digna, bem como dos anseios de segurança que advêm com a padronização de comportamento e com a previsão de sanções que caracterizará como indesejados determinados integrantes. O território das Ocupações é formado e criado segundo padrões comuns, apreendidos e ressignificados a partir das 'deficiências' do ambiente anterior de onde vieram os moradores. Drogas, violência, furtos, roubos, mau comportamento não são tolerados, sob pena de expulsão. Por outro lado, atividades recreativas, culturais e de reforço escolar foram implantadas a fim de melhorar a educação das crianças, e a divisão de tarefas - de acordo com a habilidade de cada um e com a participação de 
todos e segundo preferência por idosos e crianças - revela a assimilação de concepções objetivas de regramentos adaptadas às necessidades e anseios de cada um dos membros em particular.

Já na OZP, a cisão entre os moradores, que se consideram membros do movimento, e os 'dissidentes', reside justamente na pretensão de os membros elaborarem e se submeterem a um Regimento Interno e os 'dissidentes', não. Outra cisão deu-se no contexto ideológico: os 'membros' não aceitavam, ideologicamente, a venda de espaços dentro da ocupação, enquanto os dissidentes venderam seus espaços para terceiros.

Estas cisões descrevem as seguintes situações: i) a aceitação do Regimento Interno, a prática de atividades de manutenção do prédio e da rotina comunitária por parte do conjunto dos moradores e a aceitação do controle e punição em relação a eventuais desviantes definem a construção prática e circunstancial que, por sua vez, define e revela o raciocínio e o método destes agentes sociais em suas interações a fim de manterem-se coesos e unidos em prol do exercício do direito de morar no Centro; ii) o 'membro' é caracterizado a partir da aceitação e submissão ao conjunto destas práticas normativas, pois, do contrário, ele será definido como 'dissidente' e considerado como prejudicial à manutenção do coletivo e assim passível de expulsão do grupo; iii) a defesa de direitos sociais pelos movimentos sociais depende de convergência cultural e ideológica para a manutenção do coletivo: enquanto na OCG a unidade ideológica se mantém, na OZP, segundo os membros, foi justamente a ausência desta convergência que encurtou a vida da Ocupação.

Considerando o período pós-ocupação, a reflexividade se apresenta na construção da identidade coletiva das Ocupações. O coletivo tem seu núcleo deslocado da necessidade de integração inicial para a proteção do prédio e a solidificação da ocupação para a permanência da ocupação e para a construção de ideais comuns aos moradores. Essa reflexividade se apresenta sob duas formas fundamentais: na OZP, os líderes lamentam o fim da Ocupação, que se dera mediante dissidências de interesses e aceitação, por parte dos moradores, de deixar a ocupação, e afirmam que a desarticulação física não teria desarticulado o coletivo, sendo a identidade construída ao longo de toda a ocupação uma decorrência lógica e necessária; na OQG, os líderes, de fato, demonstram preferência pelo estabelecimento do território físico, que se constitui no prédio e que com este se confunde.

Em ambos os casos, os líderes das Ocupações apresentaram descrição da sociedade real de modo diferente da dos demais moradores, que revelaram preferir sair da Ocupação para outros lugares, caso estes outros lugares Ihes ofereçam condições de satisfazer suas necessidades e 
objetivos, como já ocorrera na OZP e como pode ocorrer na OQG, segundo palavras do líder Roberto. Para os moradores, a descrição da sociedade real está referida à obtenção de moradia digna, segundo critérios de acesso a transporte, saúde, educação, melhores rendas para si e seus familiares - o que eles afirmam poder obter morando no Centro -, mas ela também está referida à existência de casa com infraestrutura e com reconhecimento pelo poder público. Eles reconhecem que a moradia nas Ocupações é provisória, o que é confirmado pelo fato de que, na OZP, as famílias aceitaram $R \$ 20.000,00$ de indenização para sair do prédio, sem garantias prévias de que teriam para onde ir. Na OQG, as famílias aceitariam as casas do Projeto Gamboa. Observa-se, ainda, que a descrição da sociedade real, para estes moradores, inclui o reconhecimento de que o poder público está, de alguma forma, exercendo o dever de dar moradia, seja pagando indenização - valor com o qual poderiam "comprar alguma coisa" ou "pagar aluguel por um tempo" -, seja oferecendo casas populares no Centro, ainda que de qualidade desconhecida. Já quanto aos líderes, na pós-ocupação, observa-se o interesse em manter a identidade das Ocupações, o que Ihes serve de referência política perante outros movimentos políticos.

Observa-se, ainda, certa gradação entre os interesses pessoais e coletivos, inclusive em relação aos líderes. O movimento social formado por interesses coletivos e por interesses particulares articula, nessa dialética, o discurso coletivo de exercer direito de moradia digna no Centro com interesses pessoais. Estes interesses oscilam entre obter vantagem financeira (vantagem financeira significando compensação pelos gastos realizados na reforma do imóvel e também no sentido de "não dar de graça para outro", segundo afirmara Juvenal, da OZP) e manter controle sobre o grupo, como no caso dos líderes de fato Roberto e Janine em relação ao movimento OQG. Quanto a esta Ocupação, a maioria aceita sair do prédio, mas estes dois - que são os mais solicitados e aos quais mais os outros moradores se reportam - não querem sair, justamente para manter a 'coesão', ainda que com novos moradores, isto é, novos integrantes, o que se contradiz com o discurso de coletividade, reproduzido por estes mesmos líderes. Afinal, eles próprios afirmaram que um dos critérios para manter a união do grupo é evitar alta rotatividade de integrantes, dando-se preferência, como no caso de novos integrantes, a membros de famílias, e não a famílias inteiras.

\section{MOVIMENTOS SOCIAIS: O PROBLEMA DA DEFINIÇÃO DO CONCEITO}

"Sector significativo da população que desenvolve e define interesses incompatíveis com a ordem social e política existente e que os persegue por vias não institucionais, invocando 
potencialmente o uso da força física ou da coerção" (Apud SANTOS, 1995: 257). Esta definição genérica de movimentos sociais - proposta por Dalton e Kuechlercom base em movimentos sociais novos formados em países capitalistas avançados nas últimas décadas do século XX - remete ao problema da definição universal da realidade sociológica dos movimentos sociais.

Do ponto de vista teórico e conceitual, o problema da universalidade revela a diversidade da realidade dos novos movimentos sociais segundo contextos histórico-sociais específicos. Afinal, os países capitalistas - centrais e periféricos - têm produzido movimentos sociais marcadamente diversos e heterogêneos (SANTOS, 1995:258-259).

Nos primeiros, eles vão dos movimentos ecológicos aos movimentos dos consumidores, passando pelos movimentos feministas, pacifistas, antirracistas. Nos segundos, considerando o Brasil em particular, além daqueles movimentos que já superaram a fase de organização, existiram anteriormente as Comunidades Eclesiais de Base organizadas na sua relação com a Igreja Católica. O Partido dos Trabalhadores no Brasil, as lutas de natureza popular no Peru, o Sandinismo na Nicarágua, as greves nacionais de cunho cívico no Equador, na Colômbia e no Peru, as ocupações de terras pelos camponeses no México, as formas de autogestão nas favelas de metrópoles de países como Venezuela, Peru e Brasil, todas estas são experiências que permitem proceder à enumeração dos movimentos sociais no conjunto da América Latina.

No entanto, a pretensa generalidade do conceito "movimento social", associada às ideias de força social coletiva e de organização social desta força (THOMPSON, 1979) que estas experiências parecem traduzir, mais revelam caráter relativo da identidade que é construída e que constrói histórica e socialmente os movimentos sociais.

De forma específica, considerando os movimentos sociais urbanos, eles podem ser abordados segundo a perspectiva da ação social. De natureza culturalista e de influência weberiana, esta abordagem analítica é desenvolvida por Alain Touraine e define o paradigma teórico da obra do sociólogo francês segundo duas dimensões. Primeira: o comportamento social dos indivíduos e dos grupos de indivíduos constitui unidade de análise referida a situações sociais de conflito. Segundo: a ideia de movimento social supõe a noção de sujeito histórico que luta por sua emancipação. Decorre destas afirmações a visão segundo a qual a sociedade não é definida por macroestruturas ou explicada por formas elementares a priori. Como agentes sociais dos conflitos sociais, são os movimentos sociais que constroem socialmente a realidade e que constituem o objeto da sociologia da ação social de Touraine.

Revista de Direito da Cidade, vol. 08, no 1. ISSN 2317-7721 pp.331-360 346 
A obra de Alain Touraine revela deslocamento do sujeito dos movimentos sociais quanto a seus diferentes campos de investigação através da história - trabalhadores industriais, estudantes, movimentos populares na América Latina, movimentos antinucleares, o movimento Solidariedade na Polônia, movimentos de mulheres (GOHN, 2010). Este fato, no entanto, não impede reconhecer o estatuto epistemológico dos movimentos sociais na formulação teórica do sociólogo francês no que diz respeito à ideia de ação coletiva que questiona modo de dominação social generalizada (TOURAINE, 2005). "Um movimento social é sempre um protesto moral" (TOURAINE, 1997:79). Assim, todo movimento social encerra um projeto, no sentido quer de obtenção de resultados quer de contestação de determinada situação social.

Em Touraine, a definição do conceito "movimentos sociais" depende da definição do conceito "sujeito". E dois elementos definem o sujeito: sua vontade de libertação e sua ação libertadora. No entanto, a vontade e a ação do sujeito não se confundem com as experiências individuais do sujeito empírico. Elas são de natureza coletiva. Não haverá movimento social sem vontade e ação coletivas de libertação do sujeito. Não haverá compreensão da construção da realidade social sem o entendimento da atuação específicados movimentos sociais e dos sujeitos coletivos.

A categoria teórica "sujeito" está vinculada, na obra de Touraine, à outra categoria, a de "ator", que é definida segundo a orientação ou valor que o ator atribui às suas condutas e ações. Neste sentido, a articulação de ambas as categorias permite evidenciar a atuação coletiva dos indivíduos e dos grupos sociais na história de processos sociais específicos. Como categorias analíticas da realidade social, "sujeito" e "ator" interpretam e transformam aqueles indivíduos e grupos sociais em atores sociais e sujeitos históricos que constroem suas identidades e seus papéis sociais contra determinações sociais apriorísticas.

Assim, a construção e a compreensão da própria sociedade como um todo coletivo ordenado dependem da ideia de sujeito pessoal. "O sujeito não tem outro conteúdo que a produção de si mesmo" (TOURAINE, 1997:21). E na sua própria produção - de sua identidade, de seus papéis, de sua história - como sujeito histórico e como ator social, o sujeito pessoal luta por sua própria liberdade e contra as determinações sociais. Neste sentido, como "afirmação de liberdade pessoal, o sujeito é também, e ao mesmo tempo, um movimento social" (TOURAINE, 1997:21).

No entanto, sujeito e indivíduo não são ideias que se oponham no pensamento de Touraine. Considerando que sujeito é o indivíduo construído como ator, com base na vontade do 
indivíduo de ser ator de sua existência, ele reconhece que não é possível separar o indivíduo de sua situação social (TOURAINE, 1994). E a dimensão social na construção do indivíduo como sujeito implica processo de interação com o outro e de reconhecimento do outro (TOURAINE, 1997).E o outro é definido nas diferenças (classe, etnia, gênero, nacionalidade, religião, culto) que ele reconhece e que busca reconhecimento.

Num mundo globalizado e que se globaliza, os processos de interação e de reconhecimento implicam comunicação entre os diversos e distintos sujeitos. Daí a preocupação de Touraine com os mecanismos institucionais de proteção da liberdade dos sujeitos e de suas comunicações, com a condição de possibilidade de combinação da unidade social e da diversidade cultural. Para ele, a condição para que os seres humanos possam viver juntos é que os sujeitos sejam tratados de acordo com a visão de que eles resultam da combinação de suas identidades pessoais e da afirmação de suas responsabilidades enquanto seres livres.

Do contrário, não haverá saída para o dilema que opõe o ideal da universalidade das leis (da razão, da religião, da história), ideal esse que se transformou em instrumento de dominação, ao ideal da aceitação das diferenças sem limites, ideal esse que conduz à segregação ou à guerra civil (TOURAINE, 1997).

\section{SOCIEDADE E ESTADO}

Ao definir os movimentos sociais como protestos morais, Touraine rejeita a concepção tradicional segundo a qual haveria algum movimento social específico que possuísse a missão histórica de mudança estrutural do mundo com base em algum discurso igualitário de tipo republicano ou socialista que pudesse representar e traduzir um modelo ideal de sociedade de que ele seria portador (TOURAINE, 1997). Esta afirmação permite pensar o papel dos movimentos sociais menos em torno das mudanças sociais que eles poderiam produzir do que em torno da ideia de pressão social que eles poderiam exercer.

Consequentemente, seria possível não apenas pensar os movimentos sociais preocupados com a questão da ordem social, mas também o estado como agente social de mudança histórica. Quanto a esta hipótese, o estado não se constituiria como adversário contra quem lutariam os movimentos sociais. Ele deixaria mesmo de ser considerado apenas como monopólio do uso da violência física e em busca de sua legitimação.

A despeito de seus vínculos com a elite dirigente, o estado não seria mais definido de forma absoluta como aparelho do poder. Neste sentido, Touraine opera a distinção entre governo 
e estado para afirmar que não é o estado o adversário natural ou inimigo histórico dos movimentos sociais. Afinal, a história demostra que as lutas históricas dos movimentos sociais não se confundem de forma essencial com a conquista do poder político.

Segundo Touraine, os movimentos sociais se representam como agentes de liberdade, de igualdade, de justiça social ou de independência nacional. Num mundo marcado por tradições, preconceitos e privilégios, ele reconhece ainda que os movimentos sociais constituem um apelo à modernidade ou à liberação de forças novas (TOURAINE, 1978). Isto equivale a dizer que os movimentos sociais representam forças sociais determinadas num sistema mais amplo de forças sociais de uma sociedade específica.

\section{GLOBALIZAÇÃO E CIDADE}

Touraine reconhece que a utilidade do conceito "movimento social" depende de sua capacidade analítica de evidenciar as ações coletivas que, em suas especificidades, questionam forma de dominação social quanto a seus valores específicos e suas orientações gerais da sociedade, com o objetivo de retirar-Ihe sua legitimidade (TOURAINE, 1997). Questionando forma específica de dominação social, os movimentos sociais podem ser interpretados segundo sua vontade de libertação se volta para a mudança da vida ou para a transformação da sociedade, para atuar contra os poderes que controlam o mundo das instrumentalidades ou para decretar o fim da história em curso e instaurar novo processo histórico-social. Neste caso, Touraine destaca a dimensão utópica dos movimentos sociais; naquele outro, sua dimensão ideológica. Seja como for, o que caracteriza os movimentos sociais, principalmente no século XXI, é o fato de eles não se alienarem em relação à ordem vigente (TOURAINE, 1997) através do questionamento quanto ao uso social dos recursos e quanto aos modelos culturais.

Assim, ao reconhecer que os novos movimentos sociais não se voltam para criar um novo tipo de sociedade nem tampouco liberar as forças de progresso e de futuro, e sim "mudar a vida" (TOURAINE, 1994), com a defesa dos direitos humanos (direito à vida, direito à livre expressão, direito à livre escolha de estilo e história de vida pessoal), Touraine não determina o desaparecimento da dimensão política nem da realidade dos movimentos sociais nem da análise que ele faz dos mesmos.

Ocorre que a política, segundo sentido histórico instaurado pela modernidade, deixa de ser a chave de interpretação da sociedade em termos de ordem e mudança, desordem e autoridade. No século XXI, a modernidade tem sofrido as consequências da globalização econômica. Os 
problemas transnacionais de ordem financeira dominam o cenário antes protagonizado pelos conflitos internos dos estados nacionais. A economia globalizada passa a ser o alvo dos ataques dos novos movimentos sociais em sociedades de países tanto centrais quanto periféricos.

Para compreender o mundo atual, Touraine fala de um novo paradigma: o paradigma cultural. Segundo este novo paradigma, a sociedade deixa de ser compreendida como sistema integrado e referida a um sentido geral, e os valores universais são substituídos por reivindicações culturais. Decorre daí o surgimento de uma nova forma de comunitarismo, com suas reivindicações quanto a direitos culturais e com o crescimento do individualismo (TOURAINE, 2005).

"Não se trata mais de lutar pela direção dos meios de produção, e sim sobre as finalidades dessas produções culturais que são a educação, os cuidados médicos e a informação de massa" (TOURAINE, 1994:260). A luta e a defesa dos novos movimentos sociais não são apenas por direitos individuais, políticos e sociais, fundamentados na racionalidade e na universalidade e na separação entre sociedade e comunidade (TOURAINE, 2005), e sim por direitos culturais. "[Os novos movimentos sociais] defendem a liberdade e a responsabilidade de cada indivíduo, isolada ou coletivamente, contra a lógica impessoal do lucro e da concorrência. São também contra uma ordem estabelecida que decide o que é normal ou anormal, permitido ou proibido" (TOURAINE, 2005:250). Caracterizados principalmente como movimentos de afirmação dos atores culturais quanto a seus direitos específicos, os movimentos culturais são movimentos de libertação cultural, e nisto reside a natureza social dos conflitos que os caracteriza. Eles se definem não de forma social - segundo algum tipo de identificação social com ordem, grupo ou tradição -, e sim de acordo com características psicológicas e culturais específicas (GOHN, 2010).

Os novos movimentos sociais - referidos à cultura e à representação dos sujeitos da realidade social - e suas ações coletivas - referidas à transformação destes sujeitos no contexto de suas relações e de sua presença no mundo - se manifestam em cenários espaciais específicos: as cidades. "De um lado, eles atingem a sociedade via ataques à cidade: bloqueiam-se ruas, paralisase o trânsito, queimam-se carros, ocupam-se prédios abandonados, paralisam-se escolas, hospitais e serviços públicos, denunciam-se entidades que praticam atos discriminatórios etc." (GOHN, 2010:122).

Os protestos morais e as reivindicações culturais dos movimentos sociais tornam as cidades objeto de ações de contestação, mas eles também constituem as cidades em sujeito de ações de transformação. As cidades são ressignificadas. Elas passam a adquirir novos sentidos e usos: 
O lixo se transforma em novos objetos por intermédio do trabalho de uma rede que inclui catadores, separadores, recicladores, cooperados, vendedores etc. Os ambientalistas constroem atos de resistência que pressionam por mudanças nas leis e pelo fim de destruições arbitrárias do patrimônio e do ambiente construído. As mulheres sustentam, majoritariamente, as redes solidárias que trabalham pela inclusão de crianças e adolescentes nas ruas. Educadores das escolas articulam-se com grupos comunitários e desenvolvem trabalhos contra a violência e o uso de drogas (GOHN, 2010:122-123).

As distintas e diversas categorias sociais que tomam parte destas ações coletivas criam os sujeitos - no sentido que Touraine atribui à expressão - que constituem os movimentos sociais que buscam "mudar a vida" e assim ser reconhecidos como interlocutores legítimos.

De forma específica, o processo de globalização da cidade do Rio de Janeiro tem sido conduzido através de políticas públicas que se manifestam através da realização de obras públicas no âmbito de projetos de urbanização e através de mecanismos jurídico-normativos. De acordo com a Constituição da República do Brasil, " a propriedade urbana cumpre sua função social quando atende às exigências fundamentais de ordenação da cidade expressas no plano diretor" (Art. 182, parágrafo 2º). E segundo a Lei Complementar Municipal101/2009, que modifica o Plano Diretor da Cidade do Rio de Janeiro, fica o poder executivo autorizado a instituir a Operação Urbana Consorciada da Região do Porto do Rio de Janeiro - área central da capital fluminense onde estão localizados os movimentos de ocupação urbana Quilombo das Guerreiras e Zumbi dos Palmares - que tem por objetivo realizar transformações urbanísticas estruturais, melhorias sociais e valorização ambiental da Área de Especial Interesse Urbanístico. Juntamente com as Leis Complementares 102 e 105, de 2009, a Lei Complementar 101 também instituiu a Companhia de Desenvolvimento Urbano da Região do Porto do Rio de Janeiro, com o objetivo de promover a reestruturação urbana da Área de Especial Interesse Público. ${ }^{20}$ Estes instrumentos jurídiconormativos visam à implantação do Projeto Porto Maravilha e à revitalização da Zona Portuária. Em 2011, através da lei 5272, regulamentada pelo decreto 34.045, foi criada a Empresa Olímpica Municipal, órgão da Prefeitura do Rio de Janeiro que tem por objetivo coordenar a execução dos projetos e atividades municipais relacionados à Copa do Mundo de 2014 e aos Jogos Olímpicos e Paraolímpicos de $2016 .{ }^{21}$

\footnotetext{
${ }^{20}$ http://www.portomaravilhario.com.br/media/legislação/2010/06/LC101 - 23112009.pdf

${ }^{21} \mathrm{http}: / /$ www.transparenciaolimpica.com.br/empresa_olimpica_municipal.html
} 
A cidade do Rio de Janeiro passa, a partir da última década de 90, por processo de revitalização de áreas consideradas abandonadas pelo Poder Público, como a Zona Portuária, de expansão da malha rodoviária para fins de integração da zona oeste à zona sul e à zona norte, além de obras de infraestrutura e de reforma de complexos esportivos. O objetivo desta agenda é preparar a cidade para receber grandes eventos esportivos, como a Copa do Mundo de Futebol, em 2014, e os Jogos Olímpicos, em 2016 e, assim, elevar a cidade à categoria de cidade global, seja para inseri-la na economia internacional de serviços, seja para fortalecer sua posição econômica no Brasil.

A revitalização da Zona Portuária é modelo de desenvolvimento adotado por diversas outras cidades no mundo, como o Puerto Madero, em Buenos Aires e o Porto de Barcelona. A estratégia jurídico-político-econômica é o Estado formar parcerias com grupos privados, elabora plano estratégico de médio prazo pelo Estado e promover grandes eventos culturais e esportivos internacionais. No Rio de Janeiro, o cenário de interferência do Estado na gestão da cidade se consolida a partir da década de 80 , quando a crise do modelo nacional-desenvolvimentista agrava a decadência econômico-estrutural do Rio de Janeiro e leva os governantes e investidores locais a pensarem a reestruturação econômica e política de ajuste. ${ }^{22}$

A característica marcante deste modelo de desenvolvimento é a interferência direta do Estado, associando-se ao capital privado, na organização territorial da cidade. O Estado passa a ter postura ativa promovendo a integração entre os interesses público e privado: o território é organizado segundo interesses do mercado e dos serviços de ponta. O conceito econômico de cidade "importante" é remodelado para abrigar organizações de prestação de serviço, de sistema bancário internacional, de telecomunicações, de redes hoteleiras, implantando-se novas tecnologias que permitem desconcentrar os locais de produção, diferenciando-se do modelo anterior de concentração de atividades industriais em certo espaço físico (SASSEN, 2000) e do

\footnotetext{
${ }^{22}$ A crise dos anos 80 , a reestruturação econômica e a política de ajuste dos anos 90 têm repercussões específicas no Rio de Janeiro, em razão de sua economia estar há alguns decênios em decadência estrutural, cuja principal causa está no fato de ter sido historicamente depositária dos setores que se tornaram sucessivamente obsoletos no decorrer das revoluções industriais, tais como o da siderurgia e o da construção naval. Nunca conseguiu apropriar-se dos setores de ponta de bens de consumo duráveis, que se concentram em São Paulo, o que levou à instauração de uma estrutura industrial dinamizada apenas pelo mercado local. Por esse motivo, a dinâmica econômica do Rio de Janeiro sempre foi dependente do comportamento do setor terciário local, formado por um segmento moderno (financeira, da informática, do comércio) e por outro, tradicional, de serviços pessoais e das variáveis macroeconômicas que influenciam os movimentos da massa salarial. (RIBEIRO, p.70).
} 
modelo mais antigo de que a cidade seria espaço territorial que reúne as funções de comércio e de gestão política e institucional (CASTELLS, 2006).

A evolução do modo de produção industrial para o informacional é bem desenvolvido por Peter Hall, em Megacidades, Ciudades Mundiales y Ciudades Globales, onde ele traça o percurso da gestão da informação e de seus meios de propagação através dos avanços tecnológicos. Explica que, devido à facilitação de acesso à informação ao longo do último século, a redução de distâncias através de transportes mais velozes e eficazes e das modernidades tecnológicas, que permitiram a desconcentração espacial dos parques industriais, foi o modo de produção de prestação de serviços que se tornou fundamental na evolução das cidades. Os dirigentes dessa nova ordem capitalista buscam se estabelecer onde tenha acesso a serviços que Ihes garantam gerir seus negócios.

A descentralização espacial dos meios de produção capitalista não é um fator de descaracterização da cidade enquanto instituição de desenvolvimento econômico-social e de difusão de certa cultura e de paradigmas comportamentais de suas classes. Muito pelo contrário. A descentralização espacial dos meios de produção acarreta novos paradigmas de desenvolvimento econômico-social (SASSEN, 2000) e de comportamentos dos Estados e das empresas, com a ascendência de outros espaços institucionais, sobretudo os mercados globais e as sedes das corporações. Há, ainda, a existência de arranjos econômicos transnacionais com múltipla localização em mais de um país. O espaço urbano precisa, agora, oferecer outras vantagens para que as classes investidoras ali permaneçam ${ }^{23}$, fazendo-o através da difusão de sua cultura, da difusão das ofertas de laser, de segurança e de acesso a serviços de primeira necessidade, tornando a cidade atraente como local onde se possa ter qualidade de vida (HARVEY, 2009; SANTOS, 1994) e eficiência nas transações internacionais de capital e mercadorias (SASSEN, 2000). Trata-se do que Saskia Sassen conceitua "sistema urbano transnacional", almejando-se, portanto, a chamada sociedade informacional, sendo este o estágio mais desenvolvido de uma cidade global. ${ }^{24}$

23 FREITAG, Barbara.p. 117. "Por isso as cidades globais precisam ter bons aeroportos, hotéis, telecomunicações, mídia, Internet, sistema bancário, segurança, bolsas, sistemas de seguro. (...) essas cidades também necessitam de um número significativo de pessoas treinadas para assegurar esses serviços. As cidades globais também são mercados capazes de absorver e reciclar todos os fluxos (nacionais e internacionais) de capital."

${ }^{24}$ A eficácia das grandes empresas vem de sua presença em lugares estratégicos do espaço total, pontos escolhidos por elas mesmas, dos quais exerce sua ação sobre outros pontos ou zonas, diretamente ou por intermédio de outras firmas. A ação espacial das corporações não necessita da continuidade espacial (isto é, de recorte propriamente geográfico), mas da continuidade temporal. (SANTOS, 1994, p.114, 115).

Revista de Direito da Cidade, vol. 08, no 1. ISSN 2317-7721 pp.331-360 
Cidades Globais são estratégicas para o gerenciamento da economia global e para a produção dos mais avançados serviços e operações financeiras. Elas são chave para os serviços avançados e para os recursos de telecomunicações necessários para a implementação e gerenciamento de operações globais na economia. Elas também tendem a concentrar os escritórios centrais de empresas, especialmente daquelas que operam globalmente. ${ }^{25}$

A busca por profissionais também muda de perfil. Os trabalhos e profissionais que as empresas buscam precisam ser cada vez mais qualificados. A organização do trabalho assalariado e das classes trabalhadoras assalariadas -, enquanto uma das características do sistema capitalista, também sofre profunda modificação: enquanto no pós-2a Guerra Mundial houve a expansão da classe média, com incorporação dos trabalhadores às relações de mercado formal de trabalho, a partir da década de 70, as transformações tecnológicas e pela implementação da sociedade informacional e aumento da procura por prestadores de serviço, a relação demanda/oferta por carreiras estáveis se modifica:

Os empregadores tendem a procurar, pressionados pela competição internacional, pelos mercados instáveis de produtos e pelo enfraquecimento do apoio político a programas setoriais oficiais do lado da oferta, um fator fundamental tem sido a persistência de altos níveis de desemprego por mais de uma década em muitas cidades de grande porte, o que alterou notavelmente a posição de negociação dos empregadores e a insegurança ou marginalização dos grupos menos favorecidos no mercado de trabalho. Trabalhadores, desesperados por empregos, têm se mostrado dispostos a assumir empregos cada vez menos atraentes. Esses fatos, que ocorrem nas duas esferas do mercado de trabalho e com maior intensidade nos núcleos urbanos, parecem ter induzido, por um lado, a uma crescente desestabilização do emprego, fazendo com que seja cada vez mais ocasional e informal. Por outro lado, deu-se uma polarização cada vez maior de oportunidades de emprego, com novos tipos de divisão social. ${ }^{26}$

Os trabalhadores vêm para os grandes centros urbanos envolvidos na ideologia de se incluir no contexto de globalização, pretendendo se integrar à cidade global. Optam por aqui permanecerem mesmo em condições precárias de habitação, alimentação e saneamento básico. 0 Estado é chamado, então, a suprir suas necessidades básicas, mediante programas de inclusão social, de subsídio aos custos de subsistência e de financiamento e entrega de moradias, recursos de saúde e alimentação.

\footnotetext{
${ }^{25}$ SASSEN, Saskia, Cities in a world economy. p. 21, tradução livre

${ }^{26}$ SASSEN, Saskia. As cidades na economia mundial, p. 133.
} 
A política de moradia acompanha a reestruturação, contando com incentivos e programas federais, como o 'minha casa, minha vida', e com incentivos municipais e estaduais como a construção de conjuntos habitacionais e concessão de aluguel social a famílias em áreas de risco ou sem moradia. Paralelamente, movimentos sociais reivindicantes do que intitulam moradia digna, organizam-se, escolhem integrantes segundo critérios de aderência aos interesses comuns coletivos e de necessidade de moradia digna, elegem estratégias de ação a fim de pressionar o poder público, ressignificam conceitos de cidadania, luta, direito, moradia e liderança, segundo concepções do coletivo e de interesses individuais.

\section{MOVIMENTOS SOCIAIS E TERCEIRO SETOR}

O conceito "terceiro setor" está referido a dois outros setores: o primeiro setor, representado pelo Estado, e o segundo setor, definido pelo mercado. "A referência, no entanto, é indireta, obtida pela negação - 'nem governamental, nem lucrativo'. Em termos explícitos e positivos, o conceito designa simplesmente um conjunto de iniciativas particulares com um sentido público" (FERNANDES, 1994: 127).

Segundo formulação de tipo ideal, o terceiro setor pode ser definido de acordo com a síntese das seguintes características ou ideias reconhecidas ou atribuídas ao fenômeno social chamado "organização": caráter privado, dimensão institucional, ausência de fim lucrativo, cunho voluntário, autonomia, solidariedade social, inserção econômica, aceitação de riscos, realização de trabalho (SALAMON, 1999). Assim, as organizações que definem o terceiro setor são separadas do setor público, quanto às diversas formas de organização e funcionamento do governo. A institucionalidade destas organizações caracteriza a formalidade das mesmas. O principal objetivo destas organizações são os grupos sociais e comunitários. Elas existem e funcionam segundo participação voluntária de seus membros. A gestão destas organizações não depende nem de autoridades públicas nem de outras organizações, assim como a sua criação depende da livre iniciativa dos cidadãos. A solidariedade, quanto às suas diversas formas de manifestação (social, profissional, territorial), define valores que orientam essas organizações. Do ponto de vista econômico, elas realizam algum tipo de atividade produtora de bens e/ou de distribuição de serviços. Seus criadores assumem os riscos econômicos de seu funcionamento. O trabalho voluntário de que elas dependem pode associar-se também ao trabalho assalariado.

Do ponto de vista social, as organizações que participam na definição do terceiro não possuem o mesmo peso ou importância. A avaliação deste quadro depende da análise da situação 
dos países e sociedades em que elas são criadas. No entanto, sãos as organizações que produzem bens e que fornecem serviços - principalmente nas áreas da saúde e da educação - que mais participam do terceiro setor na maior parte dos países, de acordo com o The Johns Hopkins Center for Civil Society Studies.

De modo geral, a relação entre as organizações sociais do terceiro setor e os movimentos sociais pode ser estabelecida segundo uma das seguintes formas: ou as organizações do terceiro setor constituem a base de organização dos movimentos ou são os movimentos sociais que estão na base nas organizações do terceiro setor. De forma específica, a definição desta relação depende fundamentalmente da análise de conjuntura histórica e social particular.

Do ponto de vista teórico, o estudo dos movimentos sociais tem fornecido as condições de análise das organizações do terceiro setor, quanto ao que são e quanto ao papel que desempenham, em contexto histórico específico e quanto à atuação particular de grupos ou de temas igualmente específicos (TOURAINE, 1984).

No entanto, este fato não permite afirmar convergência teórica quanto ao status que as diversas formulações atribuem às organizações do terceiro setor e aos movimentos sociais, principalmente quando estes últimos são considerados segundo a clivagem "velhos" e "novos" movimentos sociais. Aquelas revelam preocupações e ações de cunho materialista, com ênfase na questão da redistribuição material, o que os aproximam dos "velhos" movimentos sociais. Já os valores dos "novos" movimentos sociais estão referidos à questão de estilo ou modo de vida.

A questão da desigualdade e dos problemas materiais de vida dos cidadãos explica a adoção de políticas públicas, mas explica também as críticas quanto aos públicos que estas políticas criam e para os quais elas se voltam (WILLIAMS, 1999). Isto permite afirmar que nem todas as formas de atuação social se constituem em movimentos sociais homogêneos, muito embora, nos anos 60, eles tenham contribuído politicamente para questionar o Estado-Providência dos países em que eles existiam. Esta contribuição permite compreender o legado desses movimentos para as organizações do terceiro setor, no que diz respeito à superação do conceito de justiça social associado à ideia de caridade (KRAMER, 1993).

Por outro lado, a heterogeneidade que caracteriza o terceiro setor permite questionar a pertinência e a legitimidade mesmo do termo "setor". Daí a adoção pela Comissão Europeia da expressão "terceiro sistema" (CIRIEC, 2000), fundamentada na ideia de abertura e pluralismo e no caráter misto e intermediário do que se entende por setor. O fato de se pensar o setor como sendo heterogêneo, por exemplo, permite que ele seja considerado não apenas como opositor e 
substituto, mas também como aliado e complementar quer do Estado quer da área mercantil (GIDRON, 1992).

O papel político das organizações do terceiro setor pode ser associado ainda aos serviços públicos que elas prestam de forma cada vez mais frequente. Este fato permite pensar o isolamento do poder público tradicional quanto aos mecanismos democráticos de prestação de contas (TAYLOR, 1996). Por outro lado, a própria heterogeneidade do terceiro setor permite questionar a natureza de interesse público de todas as reivindicações das suas organizações. A atuação destas organizações se aproxima não raro da dos grupos de interesse, particularmente na hipótese de cooptação de partidos políticos ou de fundadores, disfunção dos mecanismos de democracia interna e exigências de natureza egoística (CANDLER, 1999).

O papel político das organizações do terceiro setor pode ainda ser associado à posição que elas ocupam nas relações com o Estado, o mercado e a comunidade. Pertencendo à sociedade civil, elas fazem parte de uma postura cívica específica, de um projeto de reforma ou de um discurso (EVERS, 1995). Quanto à questão da reforma, por exemplo, é possível reconhecer que as parcerias que o Estado tem interesse de realizar com as organizações do terceiro setor estão submetidas aos critérios e requisitos legais. Sendo um dos objetivos da reforma do Estado no século XX a redistribuição de prestações de serviços públicos, de modo a solucionar a ineficiência da administração pública herdada do Estado social, o Estado permanece como regulamentador e observador dos serviços públicos diretamente prestados pela sociedade civil (DI PIETRO, 2008).

\section{CONCLUSÃO}

O conceito "terceiro setor" permitiu desconstruir a oposição clássica "sociedade civil Estado" e afirmar a existência de relações que se estabelecem sem fronteiras previamente definidas entre os termos rompidos da dicotomia. Neste sentido, protagonistas do terceiro setor e de movimentos sociais poderiam até mesmo ser identificados fora das estruturas oficiais de ordenação e controle jurídicos do Estado - e mesmo contra estas estruturas - na medida em que desempenhariam papéis que não fossem apenas críticos em relação ao Estado mas que traduzissem principalmente a organização e o funcionamento de ações coletivas voltadas para a concretização de direitos.

A investigação empírica dos movimentos de ocupação de prédios públicos abandonados no centro da cidade do Rio de Janeiro revelou que a crítica direta ao Estado e aos governantes se 
confunde com as estratégias das Ocupações voltadas para a concretização do direito à habitação na capital fluminense nesta primeira década do século XXI.

Do ponto de vista analítico-conceitual, é possível afirmar a condição de movimento social das referidas ocupações quanto ao questionamento que elas fazem da situação política e social na área da habitação na cidade do Rio de Janeiro no contexto de seu processo de reurbanização e de globalização. Por outro lado, o caráter informal das referidas Ocupações, a visão que elas possuem de que a violação do direito à habitação corresponde a serviços públicos não prestados pelo Estado e o fato de que elas próprias funcionam coletivamente para realizar o referido direito que o Estado não realiza permitem aproximar analítica e conceitualmente as referidas ocupações do terceiro setor.

No entanto, se a condição de inscrição destas ocupações no terceiro setor depende de que deste também participem os movimentos sociais, e que como tais sejam consideradas aquelas ocupações, a especificidade dos movimentos de ocupações de imóveis públicos abandonados na capital fluminense aponta numa outra direção. A informalidade destes movimentos se confunde com a ilegalidade que os caracteriza de acordo com as regras do direito oficial vigente. Ainda que não desqualifique as ocupações como movimentos sociais, a ilegalidade retira delas a condição de participação do terceiro setor. O caráter problemático da ilegalidade consiste no fato de que ela cede lugar à outra categoria de pensamento no âmbito das Ocupações: a legitimidade. Afinal, a habitação é considerada como direito de todos, sem qualquer discriminação, e o que os prédios públicos são de todos pela via dos impostos pagos. Por outro lado, a visão de que as Ocupações constituem um coletivo de forma defensiva contra o Estado impede a realização da condição de parceria entre ambos quanto à prestação de serviço público específico. Além disto, o interesse público que caracteriza as organizações sociais e as organizações da sociedade civil que definem o terceiro setor não só não define o espírito coletivo que anima as Ocupações, mas também a ele se opõe quanto a interesses particulares que explicam os conflitos e as dissensões internas nas próprias ocupações.

Se as referidas variáveis permitem definir, ou não, os movimentos de ocupação urbana como movimentos sociais e assim inscrevê-los no terceiro setor, o fato é que tais movimentos garantem repensar a relação sociedade civil - Estado quanto à sua participação histórica na engenharia social da cidade. E quanto a isto, a contribuição dos mesmos diz respeito ao questionamento político quanto ao modo democrático de gestão da cidade que eles ajudam a construir, modo esse que se opõe a políticas públicas autoritárias, de caráter vertical, que não 
levam em conta as próprias histórias de vida dos habitantes nem o impacto que as reformas urbanas que tais políticas viabilizam terão sobre eles.

\section{REFERÊNCIAS BIBLIOGRÁFICAS}

BALTIMORE. The Johns Hopkins Center for Civil Society Studies, 1999.

CANDLER, G. "Interest Groups and Social Movements: Self or Public Interested? Insights from the Brazilian Third-Sector Literature" in Voluntas 10(3), 1999.

CASTELLS, Manuel. A Questão Urbana. São Paulo. Ed. Paz e Terra. 2006.

CICOUREL, Aaron. A Etnometodologia. In: BIRBAUM, Pierre; CHAZEL, Francois. Teoria Sociológica. São Paulo: Hucitec/Edusp, 1977.

CIRIEC. The Enterprises and Organizations of the Third System.A Strategic Challenge for Employment. Liège: CIRIEC, 2000.

COMPANS, Rose. Empreendedorismo urbano: entre o discurso e a prática. São Paulo: Editora UNESP, 2005.

DI PIETRO, Maria Sylvia Zanella. Parcerias na Administração Pública. São Paulo: Atlas, 2008.

ENGELS, Friedrich. A Situação da Classe Trabalhadora na Inglaterra. São Paulo: Boitempo, 2008.

EVERS, A. "Part of the welfare Mix: The Third Sector as an Intermediate Area" in Voluntas, 6(2), 1995.

FERNANDES, Rubem César. Privado, porém público. O Terceiro Setor na América Latina. Rio de Janeiro: Relume-Dumará, 1994.

FREITAG, Bárbara. Teorias da Cidade. Campinas (SP), Papirus, 2006.

GARFINKEL, Harold. Studies in Ethnomethodology. New York: Blackwll Pub, 1992.

GARFINKEL, Harold; SACKS, Harvey.Theorical Sociology, Perspectives and Developments. New York: Appleton-Century Crofts, 1970.

GIDRON, B, KRAMER, R M, e SALAMON, L M (org.) (1992), Government and the Third Sector: Emerging Relationships in Welfare States, Jossey-Bass nonprofit sector series. San Francisco: Jossey-Bass, 1992.

GOHN, Maria da Glória. Novas Teorias dos Movimentos Sociais. São Paulo: Edições Loyola, 2010.

GRAMSCI, Antonio. Cadernos do Cárcere. Rio de Janeiro: Civilização Brasileira, 2000, v 2 [caderno 12 , §1, pp20-21]. 
Cadernos do Cárcere. Rio de Janeiro: Civilização Brasileira, 2000, v. 3[caderno 6, § 137, pp254-255].

HALL, Peter. Megaciudades, ciudadesmundiales e ciudadesglobales. In: Lo Urbano en 20 autores contemporáneos. Barcelona: Ediciones UPC. 2009.

HARVEY, David. Mundos Urbanos Posibles. In: Lo Urbano en 20 autores contemporáneos. Barcelona: $\quad$ Ediciones UPC. 2009. http://www.portomaravilhario.com.br/media/legislação/2010/06/LC101 - 23112009.pdf http://www.transparenciaolimpica.com.br/empresa_olimpica_municipal.html

KRAMER, R M et alli. Privatization in four European countries.Comparative studies in governmentthird sector relationships.Armonk, NY: M.E. Sharpe, 1993.

MYERS, Greg. Análise da Conversação e da Fala. In: BAUER, Martin W; GASKELL, George (Orgs.). Pesquisa qualitativa com texto, imagem e som; um manual prático. Petrópolis: Vozes, 2002.

RIBEIRO. Luiz Cesar de Queiroz. Cidade desigual ou cidade partida? Tendências da metrópole do Rio de Janeiro. In: RIBEIRO. Luiz Cesar de Queiroz (org). O futuro das metrópoles: desigualdades e governabilidade. pág.63 a 96. Rio de Janeiro. Ed. Revan.

SALAMON, Lester M. et al. Global Civil Society.Dimensions of the Nonprofit Sector.

SANTOS, Boaventura de Sousa. Pela Mão de Alice. O social e o político na pós-modernidade. São Paulo: Cortez, 1995.

SANTOS, Milton. A urbanização brasileira. São Paulo. HUCITEC, 1994.

SASSEN, Saskia. As cidades na economia mundial. Studio Nobel. Cities in a world economy. California. Pine Forge Press. 2000.

TAYLOR, M. Public Policy in the Community.Hampshire; Nova lorque: Palgrave Macmillan, 2003.

THOMPSON, E. P. Tradición, revuelta y consciência de classe. Barcelona : Grijalbo, 1979.

TOURAINE, Alain. La voix et le regard. Paris : Seuil, 1978. Le retour de l'acteur. Essai de sociologie. Paris: Fayard, 1984. Un nouveau paradigme. Pour comprendre le monde d'aujourd'hui. Paris : Fayard, 2005. Podremos vivir juntos ? México: Fondo de Cultura Económica, 1997. Qu'est-ce que la démocratie ? Paris : Seuil, 1994.

WILLIAMS, Fiona. "Good-enough Principles for Welfare" inJournal of Social Policy, 28(4), 1999.

Trabalho enviado em 05 de fevereiro de 2016.

Aceito em 16 de fevereiro de 2016. 